\title{
KONSEP ETIKA DALAM DAKWAH
}

\author{
Siti Rohmatul Fatihah \\ Mahasiswa Pascasarjana UIN Walisongo \\ Email: rohmatulfatihah@gmail.com
}

\begin{abstract}
Da'wah must be done with science. People who have an interest in plunging into the world of da'wah are required to understand the rules and mechanisms of dakwah fully intact before further practicing it. If one is forced to do da'wah without controlling or understanding knowledge (among other things related to ethics and aesthetics of da'wah), not only the process and the result is not good, but also the consequences can be dangerous, both for the image of Islam, da'wah, and religious life in general. Because, deeper and broader understanding and understanding of religious teachings, community life, and ways of preaching (including ethics and aesthetics), the dakwah is shown more wise, wise, touching, interesting, memorable, and longing.

Dakwah harus dilakukan dengan ilmu. Orang yang memiliki minat terjun ke dunia dakwah diwajibkan memahami aturan-aturan dan mekanisme dakwah dengan utuh secara sempurna sebelum lebih jauh mempraktikkannya. Jika seseorang memaksakan diri melakukan dakwah tanpa menuguasai atau memahami ilmu (antara lain berkaitan dengan etika dan estetika dakwah), bukan hanya proses dan hasilnya yang kurang baik, tetapi juga akibatnya dapat menjadi berbahaya, baik bagi citra Islam, dakwah, maupun kehidupan keagamaan pada umumnya. Karena, semakin dalam dan luas pemahaman serta waawasan dai terhadap ajaran agama, kehidupan masyarakat, serta cara berdakwah (termasuk di dalamnya etika dan estetika), maka dakwah yang ditunjukkan semakin arif, bijak, menyentuh, menarik, mengesankan, dan dirindukan.
\end{abstract}

Kata kunci: Dakwah, Pengertian Etika, Etika Dai, Kode Etik 


\section{A. PENDAHULUAN}

Sebagai ajakan untuk memikirkan klaim terpenting tentang hidup dan mati, kebahagiaan atau siksa yang abadi, kebahagiaan dunia atau kesengsaraan, kebajikan dan kejahatan, maka misi dakwah harus dilaksanakan dengan integritas penuh pendakwah dan objek pendakwah. Bila pihak-pihak merusak integritas ini, degan cara meminta atau menerima suap dengan menerima keuntungan, menerapkan paksaan atau tekanan, memanfaatkan demi tujuan bukan dijalan Allah, maka ini merpakan kejahatan besar dalam berdakwah atau dakwah islam menjadi tidak sah. Dakwah Islam itu harus dijalankan dengan serius, melalui aturan-aturan yang benar sehingga diterima dengan komitmen yang sama terhadap kebenaran islam. Objek dakwah harus merasa bebas dari paksaan, ancaman, serta nila-nilai yang bersifat merusak yang cenderung untuk anarki.

Karena itu para pelaku dakwah dalam hal ini da'I tidak diperintahkan menyeru islam begitu saja, ada aturan-aturan yang telah ditetapkan. Jelas dakwah islam tidak bersifat melontarkan isu-isu yang bersifat fanatis, memaksa, provokatif, celaan-celaan yang menimbulkan permusuhan, dan bukan pula aktivitas-aktivitas yang bersifat destruktif. Karena etika manusia memandang dakwah yang dipaksakan sebagai pelanggaran berat, maka itu dakwah islam mengkhususkan penggunaannya secara persuasif.

\section{B. DAKWAH}

Kata dakwah merupakan bentuk masdar dari kata yad'u dan $d a^{\prime} a$ yang artinya adalah memanggil, mengundang, mengajak, menyeru, mendorong, dan memohon. Ibnu Taimiyyah mengartikan dakwah sebagai proses usaha untuk mengajak masyarakat untuk beriman kepada Allah dan RasulNya sekaligus menaati apa yang diperintahkan Allah dan Rasul-Nya. Sementara itu, Abdul Munir Mulkhan mengartikan dakwah sebagai usaha mengubah situasi kepada yang lebih baik dan sempurna, baik terhadap individu maupun masyarakat, sedangkan Ali Mahfudz mendefinisikan dakwah sebagai upaya memotivasi umat manusia untuk melaksanakan kebaikan, mengikuti petunjuk serta memerintah mereka berbuat ma'ruf dan mencegahnya dari perbuatan mungkar agar mereka memperoleh kebahagiaan dunia dan akhirat. ${ }^{1}$ Adapun unsur-unsur dakwah menurut Muhammad Sulthonadalah Dai, mad'u, metode dakwah (uslub), media dakwah (wasilah al-da'wah), pesan dakwah (maudu'), tujuan dakwah. ${ }^{2}$

\footnotetext{
${ }^{1}$ Ilyas Supena, Filsafat Ilmu Dakwah, (Yogyakarta: Ombak, 2013), h. 89-90.

${ }^{2}$ Muhammad Sulthon, Dakwah dan Sadaqat, (Yogyakarta: Pustaka Pelajar, 2015), h. 42.
} 


\section{ETIKA DAKWAH}

\section{Pengertian Etika}

Secara etimologi, etika berasal dari bahasa Yunani, ethos (dalam bentuk tunggal) atau ta etha (jamak). Kata ethos memiliki arti tempat tinggal, padang rumput, kandang, adat, kebiasaan, akhlak, watak, perasaan, sikap, dan cara berpikir. Sedangkan dalam bentuk jamak, ta etha, artinya adat kebiasaan. Sehingga etika berarti bertindak atas dasar moralitas atau selaras dengan patokan moral yang berlaku dalam masyarakat tertentu, atau menyelaraskan perbuatan dengan standar perilaku dari suatu profesi tertentu. ${ }^{3}$

Menurut Achmad Charis Zubair, istilah etika sering diidentikan dengan susila (Sansekerta). Su yang berarti lebih baik dan Sila yang berarti dasar-dasar, prinsip, serta aturan hidup. Jadi, susila memiliki arti prinsip, dasar, atau aturan hidup yang lebih baik. Dalam Kamus Besar Bahasa Indonesia, kata etika memiliki arti; (1) ilmu tentang apa yang baik dan apa yang buruk, serta tentang hak dan kewajiban moral, (2) kumpulan asa atau nilai yang berkenaan dengan akhlak, (3) nilai mengenai benar dan salah yang dianut suatu golongan atau masyarakat.

Jadi, etika adalah nilai-nilai kebaikan yang tumbuh selama kehidupan manusia. Nilai-nilai tersebut sengaja diciptakan sebagai kebutuhan yang harus dipenuhi dalam konteks kehidupan bermasyarakat. Nilai-nilai tersebut dipelihara dan diwariskan secara turun-temurun guna menjamin kebahagiaan serta kesejahteraan. Nilai-nilai tersebut menjadi norma dan aturan yang harus dipatuhi. Pelanggaran terhadap aturan tersebut berdampak pada munculnya sanksi yang akan diterima. ${ }^{4}$

Etika juga berhubungan dengan soal baik atau buruk, benar atau salah. Etika adalah jiwa atau semangat yang menyertai suatu tindakan. Dengan demikian etika dilakukan oleh seorang untuk perlakuan yang baik agar tidak menimbulkan keresahan dan orang lain menganggap bahwa tindakan tersebut memang memenuhi landasan etika. ${ }^{5}$

Baik dan buruk berhubungan dengan kemanusiaan dan sering dikaitkan dengan perasaan dan tujuan seseorang, tidak berlaku umum dan merata. Seorang yang menganggap suatu perbuatan itu baik, belum tentu dianggap baik pula oleh orang lain, tergantung pada kebiasaan yang dipakai oleh tiap-tiap kelompok. Meskipun demikian, etika berlainan dengan adat, karena adat hanya memandang lahir, melihat tindakan yang di lakukan, sementara etika lebih memperhatikan hati dan jiwa orang yang melakukan dengan maksud apa dilakukan.

Dalam bahasa Arab, etika dikenal dengan istilah akhlak. Sehingga tidak jauh berbeda dengan etika, kecuali ketika kata akhlak ditambah dengan Islam

\footnotetext{
${ }^{3}$ Kustadi Suhandang, Ilmu Dakwah, (Bandung: PT Remaja Rosdakarya, 2013), h. 184.

${ }^{4}$ Hajir Tajiri, Etika dan Estika Dakwah, (Bandung: PT Remaja Rosdakarya, 2015), h. 12-13.

${ }^{5}$ Munir, M. Metode Dakwah, (Jakarta: Kencana, 2003), h. 15.
} 
sehinnga menjadi akhlak Islam sehingga sepadan dengan etika Islam. Menurut Ahmad Amin, etika sepadan dengan akhlak atau ilmu akhlak, yaitu ilmu yang menjelaskan arti baik dan buruk, menerangkan apa yang seharusnya dilakukan oleh sebagian manusia kepada lainnya. ${ }^{6}$

\section{Macam-Macam Etika Dakwah}

\section{a. Etika Dakwah Dai}

Etika/ akhlak dai adalah akhlak Islam yang Allah nyatakan dalam

Alquran dan Sunnah Rasul menurut Tutty Alawiyah adalah sebagai berikut:

1) Al-Shidq (benar, tidak dusta), yakni meliputi kasad (niat), perkataan dan perbuatan. ${ }^{7}$ Dai yang benar, tampak bekasan benarnya itu pada wajah dan suaranya. Allah memerintahkan setiap mukmin supaya berperilaku "benar", tidak boleh berdusta. Allah SWT berfirman : "Hai orang-orang yang beriman bertakwalah kepada Allah, dan hendaklah kamu bersama orang-orang yang benar".

2) Al-Shabr (sabar dan tabah)

Sabar terbagi menjadi tiga, yakni; sabar dalam ketaatan kepada Allah, sabar dalam meninggalkan kemaksiatan, dan sabar dalam menghadapi musibah atau bahaya.

3) Ar-rahmah (rasa kasih sayang)

4) Tawadu'(merendahkan diri, tidak sombong).

5) Suka bergaul.

6) Amanah (terpercaya), sifat utama yang harus dimiliki seorang dai. Sebelum sifat-sifat yang lain. ${ }^{8}$

Menurut Fathul Bahri AnNabiry, akhlak yang harus dimiliki dai adalah sebagai berikut:

1) Beriman

Adalah wajib bagi seorang dai untuk beriman kepada apa yang ia dakwahkan, yaitu beriman kepada Allah, malaikat-Nya, kitab-kitab-Nya, rasul-rasul-Nya, hari akhirat, juga beriman pada ketentuan-ketentuan Allah, yang baik maupun yang buruk.

2) Bertakwa

Takwa adalah pemeliharaan. Memelihara diri dari yang dilarang agama Islam serta melaksanakan ajaran Islam.

3) Ikhlas

Menurut Dr. Yusuf Al-Qaradhawi,ikhlas adalah orang yang amal perbuatannya hanya didasari dengan mengharap keridhaan Allah Swt.

${ }^{6}$ Op. Cit., Etika dan Estetika Dakwah, h. 13.

${ }^{7}$ Ilyas Ismail, Prio Hotman, Filsafat Dakwah, (Jakarta: Kencana, 2011), h. 79.

${ }^{8}$ Jum'ah Amin Abdul Aziz, Fiqih Dakwah, (Solo: Era Intermedia, 2008), h. 78. 


\section{4) Tawadhu'}

Ialah merendahkan diri dan penuh cinta kasih terhadap orang-orang yang beriman, terlebih lagi terhadap mereka yang muallaf, agar iman mereka semakin teguh.

5) Amanah

Adalah sikap yang asasi bagi seorang dai, karena merupakan hiasan bagi para nabi, para rasul, dan orang-orang shaleh.

6) Sabar dan tabah

Sabar dapat berati tabah, tahan uji, tidak mudah putus asa, tidak tergesa-gesa, juga tidak mudah marah.

7) Tawakkal

Tawakkal sealalu diirigi dengan syukur dan sabar.

8) Ramah (kasih sayang)

Kasih sayang dalan segala hal sangat diharapkan, disukai, dan dianjurkan, baik dalam syariat maupun secara akal

9) Uswah dan Qudwah Hasanah

Qudwah hasanah adalah keteladanan yang baik.

10)Cerdas dan bersih

Cerdas akalnya, memandang sesuatu secara proporsional, tidak ditambah atau dikurangi. Sedangkan bersih adalah bersih hatinya. Yakni dapat mencintai dan menyayangi orang lain.

11)Tidak memelihara penyakit hati

(Ghibah/menggunjing orang lain, takabur/kagum terhadap diri sendiri, hasut/iri hati terhadap orang lain, kikir/pelit terhadap harta atau kebaikan). ${ }^{9}$

b. Etika Mad'u

1) Menghormati dai sebagai gurnya

2) Memperhatikan keterangan yang disampaikan oleh dai.

3) Sabar dalam proses mendapatkan ilmu melalui kegiatan dakwah yang diikuti,

4) Menjaga etika di dalam majelis

5) Mengkritk degan etik. ${ }^{10}$

c. Landasan dan Etika Berdialog

Berikut ini beberapa landasan dan etika berdialog menurut Islam:

1) Kejujuran

Dialog hendaklah dibangun di atas pondasi kejujuran, bertujuan mencapai kebenaran, menjauhi kebohongan, kebathilan dan pengaburan.

2) Thematik dan objektif

Tidak keluar dari tema sebuah dialog supaya arah pembicaraan jelas dan mencapai sasaran yang diinginkan.

\footnotetext{
${ }^{9}$ Fathul Bahri An-Nabiry, Meneliti Jalan Dakwah, (Jakarta: Amzah, 2008), h. 137-229.

${ }^{10}$ Op. Cit., Etika dan Estetika Dakwah, h. `143-144.
} 
3) Argumentatif/logis

Bertujuan akhir agar lawan menyadari atau mengikuti daripada apa yang diinginkan.

4) Bertujuan untuk mencapai kebenaran

Setiap individu ataupun kelompok harus mencapai satu tujuan yaitu menampakkan dan menjelaskan kebenaran masalah yang diperselisihkan.

5) Tawadhu

Rendah hati, tidak merasa paling benar dalam berdiskusi. ${ }^{11}$

\section{KODE ETIK DAKWAH}

\section{Pengertian Kode Etik Dakwah}

Istilah kode etik lazimnya merujuk pada aturan-aturan atau prinsipprinsip yang mermuskan perilaku benar dan salah. Secara umum etika dakwah itu adalah etika islam itu sendiri dan pengertian kode etik dakwah adalah ramburambu etis yang harus dimiliki seorang juru dakwah. Namun secara khusus dalam dakwah terdapat kode etik tersendiri. Dan sumber dari rambu-rambu etis bagi seorang pendakwah adalah Al-Qur'an seperti yang telah dicontohkan Rasulullah SAW. 12

\section{Macam-Macam Kode Etik Dakwah}

Adapun kode etik dakwah diantaranya:

a. Tidak Memisahkan Antara Ucapan Dan Perbuatan

Para da'i hendaknya tidak memisahkan antara ucapan dan perbuatan, dalam artian apa saja yang diperintahkan kepada mad'u, harus pula dikerjakan oleh da'i. seorang da'i yang tidak beramal sesuai dengan ucapannya ibarat pemanah tanpa busur. Hal ini bersumber pada QS. Al-shaff:2-3 yang artinya : "Hai orangorang yang beriman, mengapa kalian mengatakan apa yang tidak kalian kerjakan? Amat besar murka disisi Allah, bahwa kalian mengatakan apa yang tidak kalian kerjakan".

b. Tidak Melakukan Toleransi Agama

Tasamuh memang dinjurkan dalam islam, tetapi hanya dalam batas-batas tertentu dan tidak menyangkut masalah agama.

c. Tidak Menghina Sesembahan Non Muslim

Kede Etik ini berdasarkan QS. Al-an'am:108

"Dan janganlah kamu memaki sesembahan-sesembahan yang mereka sembah selain Allah, karena mereka nanti akan memaki Allah dengan melampaui batas tanpa pengetahuan".

d. Tidak Melakukan Diskriminasi Sosial

Hal ini berdasarkan QS. Abasa:1-2:

\footnotetext{
${ }^{11}$ Munir, Metode Dakwah, (Jakarta: Kencana, 2006), h. 329.

${ }^{12}$ Op. Cit., Metode Dakwah, h. 16.
} 
"Dia (Muhammad) bermuka masam dan berpaling, karena telah datang seorang buta padanya".

e. Tidak Memungut Imbalan

Dalam hal ini memang masih terjadi perbedaan anatara boleh atau tidaknya memungut imbalan dalam berdakwah. Ada 3 kelompok yang berpendapat mengenai hal ini:

Mazhab Hanafi berpendapat bahwa memungut imbalan dalam berdakwah hukumnya haram secara mutlaq, baik dengan perjanjian sebelumya atau tidak.

Imam Malik bin anas, Imam Syafi'I, membolehkan memungut biaya atau imbalan dalam menyebarkan islam baik dengan perjanjian sebelunya atau tidak. Al-Hasan al-Basri, Ibn Sirin, Al-Sya'tibi dan lainnya, mereka membolehkan memungut biaya dalam berdakwah, tapi harus diadakan perjanjian terlebih dahulu.

f. Tidak Berteman Dengan Pelaku Maksiat

Berkawan dengan pelaku maksiat ini dikhawatirkan akan berdampak buruk, karena orang yang bermaksiat itu beranggapan seakan-akan perbuatan maksiatnya itu direstui dakwah, pada sisi lain integritas seorang da'i tersebut akan berkurang.

g. Tidak Menyampaikan Hal-Hal Yang Tidak Diketahui

Da'i yang menyampaikan suatu hukum, sementara ia tidak mengetahui hukum itu pasti ia akan menyesatkan umat. Seorang dakwah tidak boleh asal menjawab pertanyaan orang menurut seleranya sendiri tanpa ada dasar hukumnya. ${ }^{13}$

Hal ini berdasarkan QS. Al-Isra':36

"Dan janganlah kamu mengikuti apa yang kamu tidak mempunyai pengetahuan tentangnya. Sesungguhnya pendengaran, penglihatan dan hati, semua itu akan diminta pertanggung jawabannya."

\section{Hikmah Kode Etik Dakwah}

Rambu-rambu etis dalam berdakwah atau yang disebut dengan kode etik dakwah apabila diaplikasiakn dengan sungguh-sungguh akan berdampak pada mad'u atau oleh sang da'i. pada mad'u akan memperoleh simpati atau respon yang baik karena dengan menggunakan etika dakwah yang benar akan tergambaar bahwa islam itu merupakan agama yang harmonis, cinta damai, dan yang penuh dengan tatanan-tatanan dalam kehidupan masyarakat. Namun secara umum hikmah dalam pengaplikasian kode etik dakwah itu adalah:

Kemajuan ruhani, dimana bagi seorang juru dakwah ia akan selalu berpegang pada rambu-rambu etis islam, maka secara otomatisia akan memiliki akhlak yang mulia. Sebagai penuntun kebikan, kode etik dakwah bukan menuntun sang da'i pada jalan kebaikan tetapi mendorong dan memotivasi membentuk kehidupan yang suci dengan memprodusir kebaikan dan kebajikan yang

\footnotetext{
${ }^{13}$ Samsul Munir Amin, Ilmu Dakwah, (Jakarta: Amzah, 2009), h. 23.
} 
mendatangkan kemanfaatan bagi sang da'i khususnya dan umat manusia pada umumnya.

Membawa pada kesmpurnaan iman. Iman yag sempurna akan melahirkan kesempurnaan diri. Dengan bahasa lain bahwa keindahan etika adalah manifestasi kesempurnaan iman. Kerukunan antar umat beragama, untuk membina keharmonisan secara ekstern dan intern pada diri sang da'i.

\section{E. KESIMPULAN}

Etika berasal dari kata ethos yaitu untuk suatu kehendak baik yang tetap. Etika berhubungan dengan soal baik atau buruk,benar atau salah. Etika adalah jiwa atau semangat yang menyertai suatu tindakan. Beberapa etika dakwah yang hendaknya di lakukan oleh para juru dakwah dalam melakukan dakwahnya antara lain : sopan, jujur dan tidak menghasut.

Kode etik lazimnya merujuk pada aturan-aturan atau prinsip-prinsip yang mermuskan perilaku benar dan salah. Secara umum etika dakwah itu adalah etika islam itu sendiri dan pengertian kode etik dakwah adalah rambu-rambu etis yang harus dimiliki seorang juru dakwah. Diantara kode etik dakwah adalah sebagai berikut: Tidak Memisahkan Antara Ucapan Dan Perbuatan, Tidak Melakukan Toleransi Agama, tidak menghina sesembahan non muslim, tidak melakukan diskriminasi sosial, tidak berteman dengan pelaku maksiat, dan tidak menyampaikan hal-hal yang tidak diketahui.

Adapun hikmah menerapakan kode etik dakwah yaitu: kemajuan ruhani, sebagai penuntun kebaikan, membawa pada kesempurnaan iman, dan kerukunan antar umat beragama. Dengan penerapan etika, keberadaan dakwah akan menjadi baik dan tentunya akan lebih menjadikan dirinya mempunyai atsar yang positif bagi semua kalangan yang terlibat dalam kegiatan dakwah tersebut.

\section{DAFTAR PUSTAKA}


Amin, S, M. Ilmu Dakwah. Jakarta: Amzah, 2009.

An-Nabiry, F, B. Meneliti Jalan Dakwah. Jakarta: Amzah, 2008.

Aziz, J, Amin A. Fiqih Dakwah. Solo: Era Intermedia, 2008.

Ismail, Ilyas, P H. Filsafat Dakwah. Jakarta: Kencana, 2011.

Munir, M. Metode Dakwah. Jakarta: Kencana, 2003.

Suhandang, Kustadi. Ilmu Dakwah. Bandung: PT Remaja Rosdakarya, 2013.

Sulthon, Muhammad. Dakwah dan Sadaqat. Yogyakarta: Pustaka Pelajar, 2015.

Supena, Ilyas. Filsafat Ilmu Dakwah. Yogyakarta: Ombak, 2013.

Tajiri, Hajir. Etika dan Estika Dakwah. Bandung: PT Remaja Rosdakarya, 2015. 